SCIENTIFIC REPORT

\title{
Mycophenolate mofetil inhibits human Tenon fibroblast proliferation by guanosine depletion
}

\author{
C Heinz, K Heise, T Hudde, K-P Steuhl
}

Br J Ophthalmol 2003;87:1397-1398

Background/aim: Mycophenolate mofetil could be a useful antiproliferative drug in glaucoma filtering surgery. In this study the authors set out to investigate whether growth inhibition of mycophenolate mofetil on human Tenon fibroblasts is mediated by guanosine depletion.

Methods: Cultured human Tenon fibroblasts were incubated in various concentrations of mycophenolate mofetil with and without supplementation of guanosine.

Results: Growth inhibition was concentration dependent. The effect could be completely antagonised by guanosine supplement.

Conclusion: Human Tenon fibroblasts depend on the de novo synthesis pathway of guanosine. No sufficient salvage pathway from purine degradation appears to exist.

$\mathrm{T}$ he immunosuppressive drug mycophenolate mofetil (MMF) is widely used in solid organ transplantation. ${ }^{1}$ MMF blocks the key enzyme inosine monophosphate dehydrogenase (IMPDH) of the guanosine de novo synthesis. ${ }^{2}$ Especially in lymphocytes this leads to a shortage of guanosine and consequently to inhibition of cell proliferation. Other cells-that is, central nervous system cells employ a salvage pathway to produce guanosine from purine degradation (Fig 1).
In previous experiments we demonstrated that both short and long term incubation with MMF inhibits human Tenon fibroblast (HTF) proliferation. ${ }^{3}$ It might therefore be a potential modulator of conjunctival scarring after glaucoma surgery. It is not known whether this effect is achieved by blockage of the de novo synthesis of guanosine or via another mechanism. If guanosine is supplemented by HTF treated with MMF the growth inhibition should be bypassed if HTF employs de novo synthesis. In this study we investigated if HTF depend on de novo synthesis of guanosine or if growth inhibition is achieved in a different way.

\section{MATERIALS AND METHOD}

\section{Cell culture}

Human Tenon fibroblasts (HTF) were obtained from tissue explants of patients who underwent cataract surgery after informed written consent. After fixation of the tissue explant cells were grown as monolayers in Dulbecco's modified Eagle's medium (DMEM), supplemented with 10\% FCS, penicillin $(100$ units $/ \mathrm{ml})$, streptomycin $(100 \mu \mathrm{g} / \mathrm{ml})$, D-glucose $(4.5 \mathrm{mg} / \mathrm{ml})$, insulin $(10 \mu \mathrm{g} / \mathrm{ml}$; all Sigma, Deisenhofen, Germany), and mercapto-ethanol $\left(5 \times 10^{-5} \mathrm{M}\right.$, Sigma $)$. Primary cultures were passaged at confluence by trypsinisation into $75 \mathrm{~cm}^{2}$ tissue flasks (Falcon, Becton Dickinson, Heidelberg, Germany). Subsequent passages were divided 1:2 or $1: 3$ in DMEM with FCS of $10 \%$. Cells from passages $3-7$ were used for all experiments. During cultivation cells

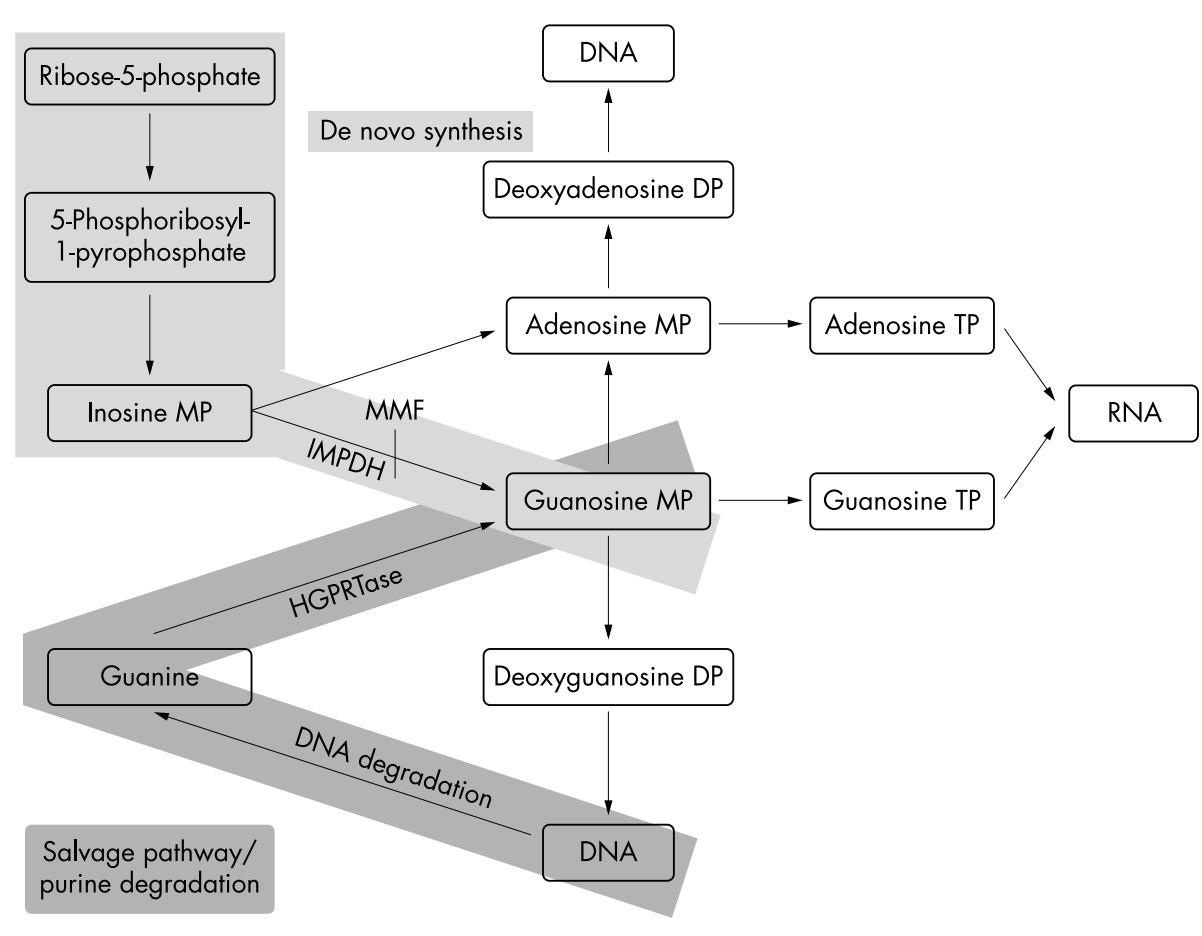

Figure 1 Purine synthesis and degradation. MMF blocks the key enzyme IMPDH of the guanosine de novo synthesis. Guanosine is also produced by a salvage pathway from purine degradation. MMF = mycophenolate mofetil; IMPDH = inosine monophoshate dehydrogenase; HGPRT = hypoxanthine phosphoribosyl transferase, MP = monophoshate; $\mathrm{DP}=$ diphosphate (modified from Karlson"1). 


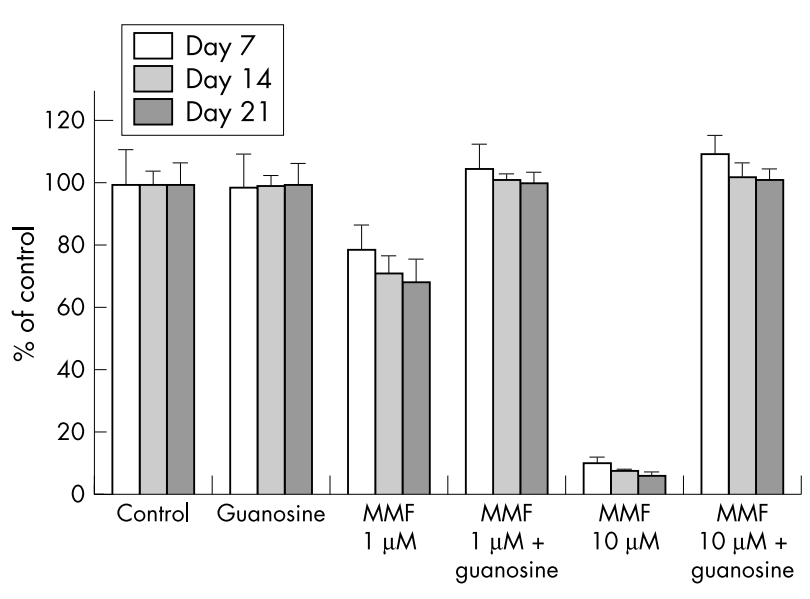

Figure 2 Effect of $1 \mu \mathrm{M}$ and $10 \mu \mathrm{M} M M F$ with and without $100 \mu \mathrm{M}$ guanosine on HTF. Growth inhibition achieved by MMF could be completely antagonised by guanosine supplementation. Results are expressed as percentage of the control of each day. Data are means (SD) of four separate experiments performed in triplicate.

exhibited the same morphological phenotype. All cells were grown at $37^{\circ} \mathrm{C}$ in a humidified incubator with $10 \% \mathrm{CO}_{2}$.

\section{Cell proliferation studies with guanosine}

A total of 200 cells per well were seeded in 96 well plates and incubated with $1 \mu \mathrm{M}$ and $10 \mu \mathrm{M}$ of MMF (Cell Cept solution for intravenous application, Roche, Grenzach-Wyhlen, Germany) or without MMF. Each of these concentrations was also incubated with $100 \mu \mathrm{M}$ guanosine (Sigma). After 7, 14, and 21 days cells were counted by staining with bisbenzimide (Sigma) $(10 \mu \mathrm{g} / \mathrm{ml})$ for 5 minutes at room temperature. Six visual fields were counted manually per well. Experiments were performed four times in triplicates.

\section{RESULTS}

Growth inhibition with MMF was concentration dependent and showed a decrease in proliferation with concentrations of $1 \mu \mathrm{M}$ and $10 \mu \mathrm{M}$ of MMF (Fig 2). There was no statistical significance between proliferation rate at day 7,14 , and 21 . At day 7 growth inhibition was slightly lower compared to day 14 and 21 . Incubation with $1 \mu \mathrm{M}$ of MMF showed a proliferation rate of $79 \%$ at day $7,71 \%$ at day 14 and $68 \%$ at day 21 . When incubated with $10 \mu \mathrm{M}$ of MMF the proliferation rate was $10 \%, 8 \%$, and $6 \%$.

Compared with the control proliferation rate at each day there was statistical significance. For example $1 \mu \mathrm{M}$ of MMF showed a proliferation rate of $71 \%$ (SD 6.4; $\mathrm{p}<0.001$ ) compared with the control (100\%) after 14 days. When incubated with $10 \mu \mathrm{M}$ of MMF the proliferation rate was reduced to $7.7 \%$ (SD 0.9; $<<0.001$ ). After 3 weeks $1 \mu \mathrm{M}$ of MMF leads to a proliferation rate of $71 \%$ (SD 7.6; $<<0.001$ ), $10 \mu \mathrm{M}$ to $6.3 \%$ (SD $0.7 ; \mathrm{p}<0.001$ ). Cell counts in wells supplemented with $100 \mu \mathrm{M}$ guanosine were statistically equal to control.

\section{DISCUSSION}

Long standing success of trabeculectomies depends primarily on the healing response of subconjunctival Tenon fibroblasts. Antiproliferative agents such as mitomycin C (MMC) and 5fluorouracil (5-FU) are widely used to modulate wound healing by a long term growth arrest and have therefore improved the success rate of trabeculectomies. ${ }^{45}$ But growth arrested HTF still produce growth factors which lead to a scarring response of surrounding unaffected HTF. ${ }^{6}$ This may explain, why in some patients glaucoma filtration surgery fails despite the use of antiproliferative agents. Because of that complete success is not guaranteed and also some major complications such as late bleb leakage or endophthalmitis are known. ${ }^{78}$

The use of the immunosuppressive MMF is a new approach to modulate wound healing. Inhibition of HTF proliferation by MMF is dose dependent. Concentrations leading to notable growth inhibition are not cytotoxic. ${ }^{3}$ Our experiments show that HTF are sensitive to guanosine depletion comparable to lymphocytes. In HTF no sufficient salvage pathway exists to produce guanosine from purine degradation.

Protein growth factors play also a substantial part in regulation of wound healing. Transforming growth factor $\beta 2$ (TGF $\beta 2$ ) especially is known to have major stimulating effects on scarring. ${ }^{9}$ In the first clinical trials downregulation by blockage with TGF $\beta 2$ antibody was shown to be safe and led to a greater fall of intraocular pressure with a slightly lower intervention rate in a small series. ${ }^{10}$ Further experiments are therefore necessary to prove whether MMF also inhibits cytokine production by interference with RNA synthesis, as well as DNA synthesis. MMF could be a useful antiproliferative drug in glaucoma filtering surgery.

\section{Authors' affiliations}

C Heinz, K Heise, T Hudde, K-P Steuhl, Department of Ophthalmology, University of Essen, Hufelandstrasse 55, 45122 Essen, Germany

Correspondence to: Carsten Heinz, MD, Department of Ophthalmology, University Essen, Hufelandstrasse- 55, 45122Essen, Germany; carsten.heinz@gmx.net

Accepted for publication 23 March 2003

\section{REFERENCES}

1 Lipsky JJ. Mycophenolate mofetil. Lancet 1996;348:1357-9.

2 Allison AC, Kowalski WJ, Muller CJ, et al. Mycophenolic acid and brequinar, inhibitors of purine and pyrimidine synthesis, block the glycosylation of adhesion molecules. Transplant Proc 1993;25:67-70.

3 Heinz C, Hudde T, Heise K, et al. Antiproliferative effect of mycophenolate mofetil on cultured human Tenon fibroblasts. Graefes Arch Clin Exp Ophthalmol 2002;240:408-14.

4 Chen CW, Huang HT, Bair JS, et al. Trabeculectomy with simultaneous topical application of mitomycin-C in refractory glaucoma. J Ocul Pharmacol 1990;6:175-82.

5 The Fluorouracil Filtering Surgery Study Group. Five-year follow-up of the Fluorouracil Filtering Surgery Study. Am J Ophthalmol 1996;121:349-66.

6 Daniels JT, Occleston NL, Crowston JG, et al. Effects of antimetabolite induced cellular growth arrest on fibroblast-fibroblast interactions. Exp Eye Res 1999;69:117-27.

7 Akova YA, Bulut S, Dabil H, et al. Late bleb-related endophthalmitis after trabeculectomy with mitomycin C. Ophthalmic Surg Lasers 1999;30:146-51.

8 Belyea DA, Dan JA, Stamper RL, et al. Late onset of sequential multifocal bleb leaks after glaucoma filtration surgery with 5-fluorouracil and mitomycin C. Am J Ophthalmol 1997;124:40-5.

9 Cordeiro MF, Bhattacharya SS, Schultz GS, et al. TGF-beta1, -beta2, and -beta3 in vitro: biphasic effects on Tenon's fibroblast contraction, proliferation, and migration. Invest Ophthalmol Vis Sci 2000;41:756-63.

10 Siriwardena D, Khaw PT, King AJ, et al. Human antitransforming growth factor beta(2) monoclonal antibody - a new modulator of wound healing in trabeculectomy: a randomized placebo controlled clinical study. Ophthalmology 2002;109:427-31.

11 Karlson P. Kurzes Lehrbuch der Biochemie für Mediziner und Naturwissenschaftler, 13th ed. Stuttgart: Georg Thieme Verlag, 1988. 